\title{
Bortezomib-mediated expression of p27Kip1 through S-phase kinase protein 2 degradation in epithelial ovarian cancer
}

\author{
Shahab Uddin ${ }^{1,4}$, Maqbool Ahmed ${ }^{1,4}$, Azhar R Hussain ${ }^{1}$, Zeenath Jehan ${ }^{1}$, Fouad Al-Dayel ${ }^{2}$, Adnan Munkarah³, \\ Prashant Bavi ${ }^{1}$ and Khawla S Al-Kuraya ${ }^{1}$
}

S-phase kinase protein 2 (SKP2), an F-box protein, targets cell-cycle regulators including cyclin-dependent kinase inhibitor p27Kip1 through ubiquitin-mediated degradation. SKP2 is frequently overexpressed in variety of cancers. We investigated the function of SKP2 and its ubiquitin-proteasome pathway in a large series (156) of epithelial ovarian cancer (EOC) patient samples, using a panel of cell lines, and nude mouse model. Using immunohistochemistry, we detected SKP2 in 13.2\% tumor samples and found that it was inversely associated with p27Kip1. EOC subset with high level of SKP2 and low level of p27Kip1 showed a strong association with proliferative marker Ki167 $(P<0.0014)$. Treatment of EOC cell lines with bortezomib or expression of siRNA of SKP2 causes downregulation of SKP2 and accumulation of p27Kip1. In addition, co-treatment of EOC with bortezomib and cisplatin causes more pronounced effect on cell proliferation, apoptosis and downregulation of SKP2 leading to accumulation of p27kip1. Bortezomib treatment of EOC cells causes apoptosis by involving mitochondrial pathway, activation of caspases and downregulation of XIAP, and survivin. Finally, treatment of EOC cell line xenografts with bortezomib resulted in growth inhibition of tumors in nude mice through downregulation of SKP2 and accumulation of p27Kip1. Altogether, our results suggest that SKP2 and ubiquitin-proteasome pathway may be a potential target for therapeutic intervention for treatment of EOC.

Laboratory Investigation (2009) 89, 1115-1127; doi:10.1038/labinvest.2009.75; published online 27 July 2009

KEYWORDS: proteasome; SKP2; p27Kip1; apoptosis; epithelial ovarian cancer

Epithelial ovarian cancer (EOC) accounts for more than $80 \%$ of human ovarian cancer and associated with high mortality rate. $^{1,2}$ Despite the availability of surgery and chemotherapeutic agent, recurrence rates are still high. In the past decade, extensive research has been made in the development of new therapeutic regiments for EOC.

The proteasome is an intracellular multicatalytic complex, which together with the two regulators PA28 (also called proteasome 11S) and PA700 (also called proteasome 19S) forms the $26 \mathrm{~S}$ proteasome. ${ }^{3,4}$ This constitutes the ubiquitinproteasome system and regulates a number of intracellular proteins that govern cell-cycle tumor, growth and survival by degrading a number of different polypeptides important for cell-cycle progression and apoptosis. ${ }^{5-7}$ The main rate-limit- ing regulator for p27Kip1 degradation has been recently identified as an SCF-type ubiquitin ligase complex that contains S-phase kinase protein 2 (SKP2) as the specific substrate-recognition subunit. ${ }^{8-10}$ SKP2 specifically binds p27Kip1 and targets it for degradation by the ubiquitin proteolytic system. Recently it has been shown that overexpression of SKP2 in mantle cell lymphoma decreased p27Kip1 expression level, whereas inhibition of SKP2 by siRNA increased p27Kip1 and p21waf1 levels. ${ }^{8-11}$ The important function of SKP2 in controlling p27Kip1 levels has been reported in a number of human cancers, including colorectal, breast, prostate and oral squamous cell carcinomas. ${ }^{12-15}$

The main mechanism of action of antineoplastic agents is their ability to induce apoptosis. There is increasing evidence

\footnotetext{
'Department of Human Cancer Genomic Research, King Fahad National Centre for Children's Cancer and Research, King Faisal Specialist Hospital and Research Centre, Riyadh, Saudi Arabia; ${ }^{2}$ Department of Pathology, King Faisal Specialist Hospital and Research Centre, Riyadh, Saudi Arabia and ${ }^{3}$ Department of Gynecology, King Faisal Specialist Hospital and Research Centre, Riyadh, Saudi Arabia

Correspondence: Dr KS Al-Kuraya, MD, FCAP, Department of Human Cancer Genomic Research, King Fahad National Centre for Children's Cancer and Research, King Faisal Specialist Hospital and Research Centre, MBC 98-16, PO Box 3354, Riyadh 11211, Saudi Arabia.

E-mail: kkuraya@kfshrc.edu.sa

${ }^{4}$ These authors contributed equally to this work.

Received 24 March 2009; revised 3 June 2009; accepted 4 June 2009
} 
indicating that proteasome inhibitors, such as the peptide aldehyde PSI, selectively inhibit the chymotrypsin-like activity of the proteasome and suppress the proliferation of human cancer cells by causing apoptosis or cell-cycle arrest or both. ${ }^{16-20}$ The proteasome inhibitor, bortezomib (Velcade), has been approved by the US Food and Drug Administration for the treatment of multiple myeloma and mantle cell lymphoma patients who had received at least one prior therapy and many clinical trials are ongoing to examine the efficacy of bortezomib for the treatment of other malignancies. $^{21}$

In this study, we first show, using immunohistochemical analysis on a large tissue microarray (TMA) of 156 EOC samples, that low expression of p27Kip1 and high expression of SKP2 can identify a clinically distinct subgroup of EOC characterized by higher proliferation. We then show that bortezomib treatment of EOC cell lines can interfere with SKP2-mediated p27Kip1 turnover by stabilizing or upregulating the expression of p27Kip1 and increasing the degradation of SKP2 protein, in vitro and in vivo. Furthermore, EOC cells treated with this specific proteasome inhibitor, bortezomib, show cell growth arrest and apoptosis by activation of the caspase cascade and disruption of the mitochondrial equilibrium. Finally, our data show the growth of EOC cell line xenografts is inhibited by bortezomib treatment due to downregulation of SKP2 and upregulation of p27Kip1. Altogether these results suggest that proteasome inhibitors may have a great utility in the treatment of EOC.

\section{MATERIALS AND METHODS Reagents and Antibodies}

Bortezomib (Velcade) was a gift from Millennium Pharmaceuticals Inc. (Cambridge, MA, USA). MG132 was purchased from Calbiochem (San Diego, CA, USA). Antibodies against cleaved caspase-3 and BID were purchased from Cell Signaling Technologies (Beverly, MA, USA). Antibodies against cytochrome $c, \beta$-actin, caspase- 3 and PARP were purchased from Santa Cruz Biotechnology Inc. (Santa Cruz, CA, USA). XIAP, cIAP1 and caspase-8 antibodies were purchased from R\&D (USA). Annexin V was purchased from Molecular Probes (Eugene, OR, USA). Apoptotic DNA Ladder Kit was obtained from Roche (Penzberg, Germany).

\section{Patient Selection and Tissue Microarray Construction}

A total of 156 patients with ovarian carcinoma diagnosed from 1991 to 2007 were selected from the files of the King Faisal Specialist Hospital and Research Centre. All samples were analyzed in a TMA format. Two cores of ovarian carcinoma were arrayed from each case. The institutional review board of the King Faisal Specialist Hospital and Research Centre approved the study.

The patients were diagnosed histologically and received follow-up care in the Department of Obstetrics and Gynecology and Department of Oncology at King Faisal Specialist Hospital and Research Centre. The histological subtype of each ovarian tumor sample was determined according to accepted criteria. ${ }^{22}$ Department of Obstetrics and Gynecology, King Faisal Specialist Hospital and Research Centre provided long-term follow-up data for these patients. The primary pathological diagnosis was serous 125 patients $(80.1 \%)$, endometrioid in $22(14.1 \%)$, clear cell in $4(2.6 \%)$ and undifferentiated/mixed epithelial in $5(3.2 \%)$. The ages of the patients ranged from 19 to 86 years, with a median age of 56 years. The majority of patients underwent primary surgical staging or cytoreduction. In some patients who were not fit for primary surgery, primary neoadjuvant chemotherapy was followed by interval debulking surgery. The distribution by FIGO stage at diagnosis was stage I-II in 8 patients $(5.1 \%)$, stage III-IV in $137(87.8 \%)$ and unknown in $11(6.1 \%)$. The median follow-up time was 14.9 months (range, 2-130 months). Progression-free survival was computed from date of surgery for patients who underwent primary cytoreduction and from date of diagnosis by biopsy or cytology in those who underwent primary neoadjuvant chemotherapy. Because the majority of patients are lost to follow-up as their disease reaches its terminal stages, it was impossible to determine overall survival in this specific patient population.

\section{Tissue Microarray Construction}

Tissue microarrays were constructed from formalin-fixed, paraffin-embedded ovarian cancer specimens as described previously. ${ }^{23,24}$ Tumor regions were mapped by a pathologist for coring. The TMA was constructed with $0.6-\mathrm{mm}$ diameter cores spaced $0.8 \mathrm{~mm}$ apart using a modified tissue microarrayer (Beecher Instruments, Sun Prairie, WI, USA). The TMA block was cut into $5 \mathrm{~mm}$ sections, adhered to the slide by an adhesive tape transfer method (Instrumedics Inc., Hackensack, NJ, USA) and UV cross-linked.

\section{Immunohistochemistry}

Tissue microarray slides were processed and stained manually. The immunohistochemistry (IHC) protocol was followed as mentioned before. ${ }^{25}$ The streptavidin-biotin peroxidase technique with diaminobenzidine as chromogen was applied. The primary antibodies were diluted in a $1 \%$ solution of bovine serum albumin in phosphate-buffered saline (PBS) and incubated overnight at room temperature. Primary antibodies used, their dilutions and cutoff levels for evaluation are listed in Supplementary Table 1. For antigen retrieval, Dako Target Retrieval Solution ( $\mathrm{pH}$ 9.0; catalog number S2368) was used, and antigen retrieval was carried out in a pressure cooker. The Dako Envision Plus System kit was used as the secondary detection system with DAB as chromogen. All slides were counterstained with hematoxylin, dehydrated, cleared and mounted. Negative controls included replacement of the primary antibody with no reacting antibodies of the same species. Only fresh cut slides were stained simultaneously to minimize the influence of slide aging and maximize reproducibility of the experiment. 
Because intensity varies between cases due to different tissue preservation, only the relative proportion (percentage) of positively stained tumor cells and the findings were recorded in $10 \%$ increments. For each case, the core with the highest percentage of tumor cells stained was used for analysis. Cases were considered positive if $50 \%$ or more of tumor cells were stained positive for p27Kip1 and SKP2. Normal SKP2 expression was defined as $<50 \%$ of tumor cells showing SKP2 expression and $\geq 50 \%$ of tumor cells showing p27Kip1 expression was considered as normal p27Kip1 expression. This cutoff was chosen based on prior analysis on some of the markers and similar cutoff used by others with TMA. ${ }^{26-29}$

\section{Statistics}

All statistical analysis was performed using the StatView JMP software (version 7.0). Differences between two independent groups were determined by the two-sided Fisher's exact test. $\chi^{2}$-Test was used to assess associations between categorical variables. Kaplan-Meier survival analyses were carried out for disease-free survival, using the log-rank test for differences between groups. Results were considered statistically significant when $P$-value from a two-tailed test was $<0.05$.

\section{Cell Culture}

Epithelial ovarian cancer cell lines SKOV3 and MDAH2774 cells were cultured in RPMI 1640 medium supplemented with $10 \%(\mathrm{vol} / \mathrm{vol})$ fetal bovine serum, $100 \mathrm{U} / \mathrm{ml}$ penicillin and $100 \mathrm{U} / \mathrm{ml}$ streptomycin at $37^{\circ} \mathrm{C}$ in humidified atmosphere containing $5 \% \mathrm{CO}_{2}$.

\section{In Vivo Tumor Xenograft Studies}

Nude mice (6-week old) were obtained from Jackson Laboratories (Maine, USA) and maintained in a pathogenfree animal facility at least 1 week before use. All animal studies were performed in accordance with institutional guidelines. For xenograft study, mice were inoculated subcutaneously (s.c.) into the right abdominal quadrant with five million MDAH2774 cells in $200 \mu \mathrm{l}$ PBS. After 1 week, mice were randomly assigned into two groups receiving either bortezomib or $0.9 \%$ saline. Treatment with bortezomib ( 1 and $2 \mathrm{mg} / \mathrm{kg}$ ) was given intraperitoneally (i.p.) twice weekly. The control group received the vehicle alone at the same schedule. The body weight of each mouse was monitored weekly and tumor volume was measured as described previously. ${ }^{28}$ After 4 weeks treatment, mice were killed and individual tumors were weighed and then snap-frozen in liquid nitrogen for storage.

\section{3-(4,5-Dimethylthiazol-2-YI)-2,5-Diphenyltetrazolium Bromide (MTT) Assays}

A total of $10^{4}$ cells were incubated in triplicate in a 96-well plate in the presence or absence of indicated test doses of bortezomib in a final volume of $0.20 \mathrm{ml}$ for $24 \mathrm{~h}$. The ability of bortezomib to suppress cell growth was determined by
MTT cell proliferation assays, as previously described. ${ }^{29}$ Replicates of three wells for each dosage including vehicle control were analyzed for each experiment.

\section{DNA Laddering}

DNA laddering assay was performed as described earlier. ${ }^{30}$ Briefly, $2 \times 10^{6}$ cells were treated with and without bortezomib for $24 \mathrm{~h}$. The cells were then harvested and resuspended in $200 \mu \mathrm{l} 1 \times$ PBS. Then $200 \mu \mathrm{l}$ lysis buffer containing $6 \mathrm{M}$ guanidine $\mathrm{HCl}, 10 \mathrm{mM}$ urea, $10 \mathrm{mM}$ Tris- $\mathrm{HCl}$ and $20 \%$ Triton X (vol/vol, $\mathrm{pH} 4.4$ ) was added to the cells and incubated for $10 \mathrm{~min}$ at room temperature. Isopropanol $(100 \mu \mathrm{l})$ was added and shaken for $30 \mathrm{~s}$ on a vortex. Then samples were passed through a filter and spun at $4500 \mathrm{~g}$ for $1 \mathrm{~min}$ and the supernatant was discarded. The pellets were washed three times with wash buffer containing $20 \mathrm{mM} \mathrm{NaCl}, 2 \mathrm{mM}$ Tris- $\mathrm{HCl}$ and $80 \%$ ethanol. The pellets were then transferred into a new $1.5-\mathrm{ml}$ tube and eluted with $200 \mu \mathrm{l}$ prewarmed elution buffer. After measuring the DNA, $2 \mu \mathrm{g}$ DNA was electrophoresed on a $1.5 \%$ agarose gel containing ethidium bromide at $75 \mathrm{~V}$ for $2 \mathrm{~h}$ and visualized using a UV light source.

\section{Annexin V/Propidium lodide Dual Staining}

Epithelial ovarian cancer cell lines were treated with the indicated concentrations of bortezomib. The cells were harvested and the percentage of cells undergoing apoptosis was measured by flow cytometry after staining with fluorescein-conjugated Annexin V and propidium iodide (PI; Molecular Probes) as previously described. ${ }^{31}$

\section{Gene Silencing Using siRNA}

SKP2 siRNA (catalog nos. S100287819 and S102659692 pooled) and scrambled control (catalog no. 102781) siRNA were purchased from Qiagen. For transient expression, cell lines were transfected by using LipofectAMINE 2000 reagent (Invitrogen) according to the manufacturer's instructions. After incubating the cells for $6 \mathrm{~h}$, the lipid and siRNA complex was removed and fresh growth medium was added. Cells were lysed $48 \mathrm{~h}$ after transfection and specific protein levels were determined by western blot analysis with specific antibodies against the targeted proteins and actin as a loading control.

\section{Cell Lysis and Immunoblotting}

Cells were treated with proteasome inhibitor as described in the legends and lysed as previously described. ${ }^{32}$ Proteins (15$20 \mu \mathrm{g})$ were separated by SDS-PAGE and transferred to polyvinylidene difluoride (PVDF) membrane (Immobilon, Millipore, Billerica, MA, USA). Immunoblotting was performed with different antibodies and visualized by the enhanced chemiluminescence (Amersham, Piscataway, NJ, USA) method. 


\section{Measurement of Mitochondrial Membrane Potential}

Epithelial ovarian cancer cells were treated with bortezomib for $48 \mathrm{~h}$, washed twice with PBS and suspended in mitochondrial incubation buffer. JC1 was added to a final concentration of $10 \mu \mathrm{M}$ and cells were incubated at $37^{\circ} \mathrm{C}$ in dark for $15 \mathrm{~min}$. Cells were then washed twice with PBS and resuspended in $500 \mu \mathrm{l}$ of mitochondrial incubation buffer and mitochondrial membrane potential (percent of green and red aggregates) was determined by flow cytometry as described previously. ${ }^{33}$

\section{Assays for Cytochrome c Release}

The release of cytochrome $c$ from mitochondria was assayed as described earlier. ${ }^{34}$ Briefly, cells were treated with and without proteasome inhibitor as described in figure legends, harvested and resuspended in hypotonic buffer. Cells were homogenized and cytosolic as well as mitochondrial fractions were isolated by differential centrifugation. Protein $(20-28 \mu \mathrm{g})$ from cytosolic and mitochondrial fractions of each sample was analyzed by immunoblotting using an anti-cytochrome $c$ antibody.

\section{RESULTS \\ Expression of SKP2 and p27Kip1 in EOC Tumors}

Levels of SKP2 and p27Kip1 were examined by immunohistochemistry in a series of 156 EOC. Representative information was available for 151 of 156 spots for SKP2 expression and 148 of 156 spots for p27Kip1. A typical case, shown in Figure 1a, illustrates the decrease in nuclear staining of p27Kip1, increased levels of SKP2 and Ki-67 in tumor sample compared with low SKP2, Ki-67 and high p27Kip1 expression in another EOC tumor sample. SKP2 overexpression was seen in 20 of $151(13.2 \%)$ and loss of p27Kip1 expression was seen in 68 of $148(46.0 \%)$ EOC samples analyzed. SKP2 expression showed a significant inverse correlation with p27Kip1 expression $(\rho=-0.2337$; $P=0.0044$, Spearman's $\rho$ correlation; Supplementary Figure 1), which is in concordance to previous findings. ${ }^{35}$ As described in 'Material and methods', SKP2 expression and p27kip1 were considered normal if nuclear staining was seen in $\geq 50$ and $<50 \%$ of tumor nuclei, respectively. We further stratified all our EOC cases into four groups depending on the presence of SKP2 expression and p27Kip1 expression
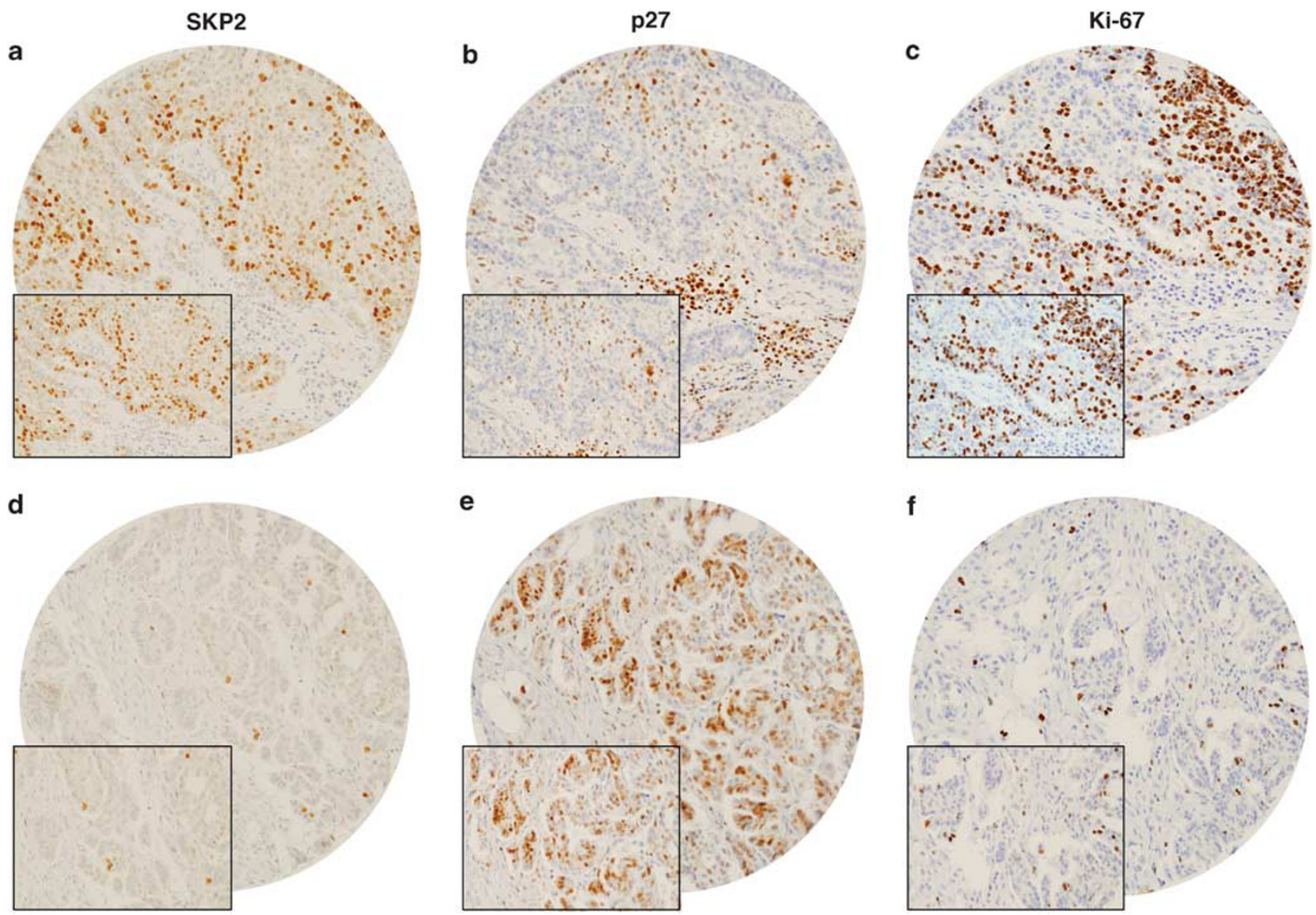

Figure 1 Tissue-microarray-based immunohistochemical analysis of SKP2, p27Kip1 and Ki-67 in epithelial ovarian cancer (EOC) patients. Array spot showing overexpression of SKP2 (a), low expression of p27Kip1 (b) and high expression of proliferative marker Ki-67 (c). In contrast, another EOC tissue array spot showing low expression of SKP2 (d), high expression of p27Kip1 (e) and low expression of Ki-67 (f). Original magnification $\times 20$ with the inset showing a $\times 100$ magnified view of the same. 
Table 1 Correlation between SKP2 and P27 status in EOC

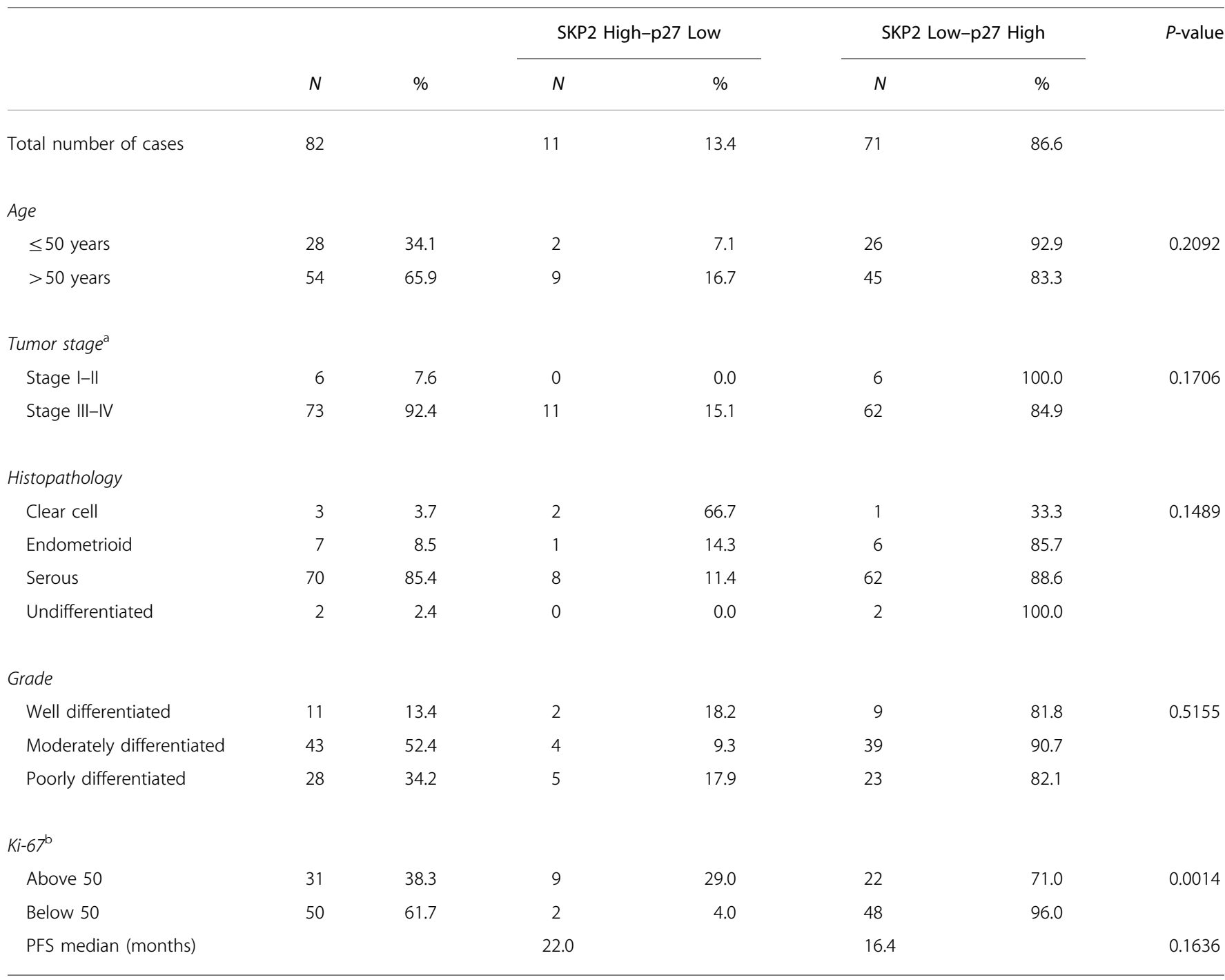

PFS, progression-free survival.

a Stage was not available for 3 tumors.

${ }^{\mathrm{b}} \mathrm{Ki}-67$ score was not available in one tumor and was attributed to missing or nonrepresentative spots in the tissue microarray section scored for Ki-67.

status: SKP2 overexpression/normal p27Kip1 group $(n=09)$, normal SKP2/normal p27Kip1 group $(n=71)$, SKP2 overexpression/low p27Kip1 expression group $(n=11)$ and EOC with normal SKP2 expression/low p27kip1 expression $(n=56)$. Of these four groups two subgroups of EOC showed inverse association between SKP2 and p27kip1: one EOC subgroup showed high SKP2 $(\geq 50)$ and low p27kip1 $(<50)$ expression; and the other EOC subgroup showed normal (low) SKP2 expression $(<50)$ and normal (high) p27kip1 ( $\geq 50$ ) expression. These two subgroups showing inverse associations between SKP2 and p27kip1 expression were selected for further analysis. The clinicopathological and the immunohistochemical analyses of the above subset 82 EOC patients are summarized in Table 1. Such stratification showed significant association of SKP2 overexpression/loss of p27Kip1 EOC group with overexpression of proliferative marker Ki-67 $(P<0.0014)$.

\section{Proteasomal Inhibition Induces $\mathbf{G}_{2}-\mathbf{M}$ Cell-Cycle Arrest through Downregulation of SKP2 in EOC Cell Lines}

We used MDAH2774 and SKOV3, EOC cell lines to determine whether inhibition of proteasome pathways by specific inhibitor leads to growth inhibition of these cancer cell lines. EOC cells were treated with various doses of bortezomib for $48 \mathrm{~h}$ and cell proliferation was determined by MTT assays. As shown in Figure 2a, bortezomib caused a dose-dependent growth inhibition in these cell lines.

To test whether the reduced growth of EOC cell lines by proteasome inhibition is associated with cell-cycle dysregulation, MDAH2774 cells were treated with various doses 


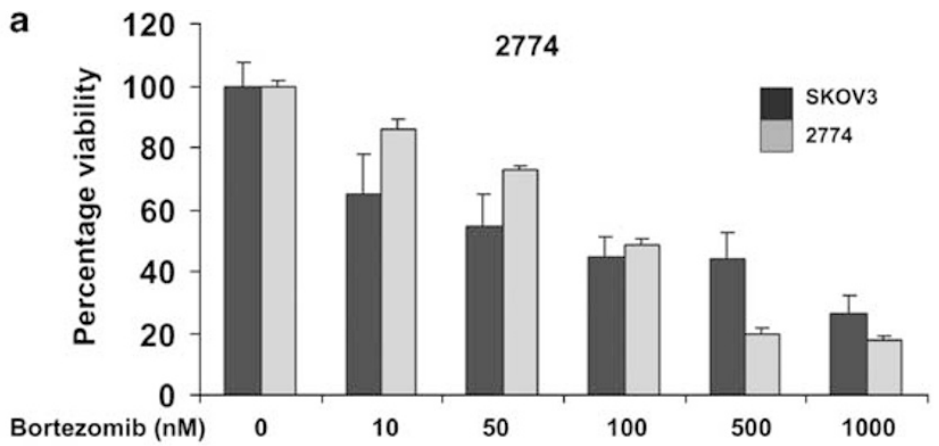

b
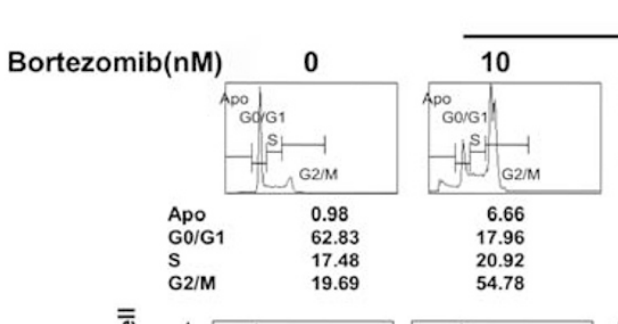

2774
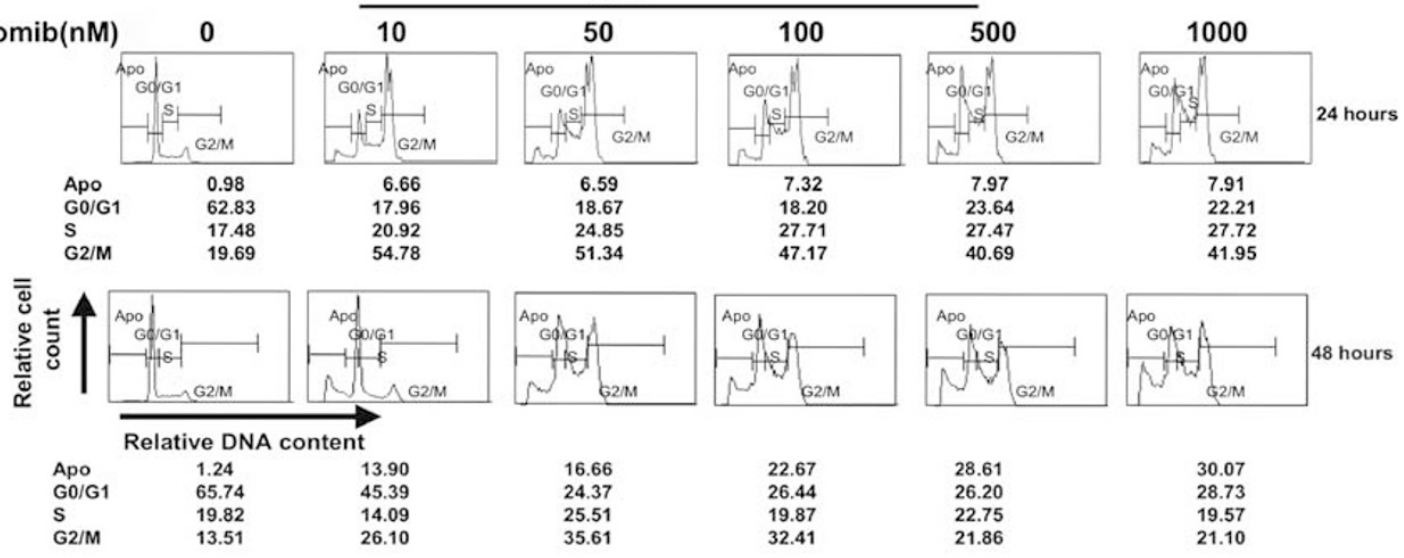

$$
\begin{aligned}
& 22.67 \\
& 26.44 \\
& 19.87 \\
& 32.41
\end{aligned}
$$

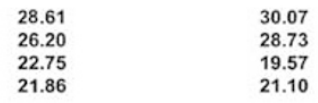

C

Bortezomib(nM) $\quad 0$

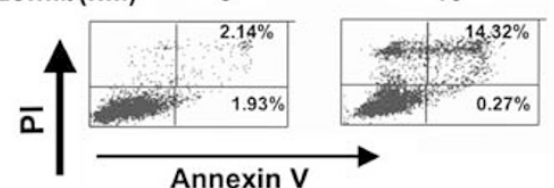

Annexin V
50

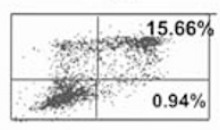

100

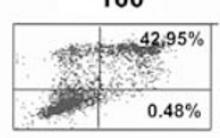

500

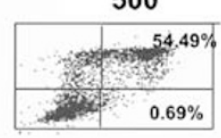

30.07

28.73

21.10

Figure 2 (a) Bortezomib inhibits the proliferation of EOC cell lines. MDAH2774 and SKOV3 cells were incubated with 10, 50, 100, 500 and 1000 nM Bortezomib for $48 \mathrm{~h}$. Cell proliferation assays were performed using MTT as described in Materials and Methods. The graph displays the mean \pm s.d. (standard deviation) of three independent experiments with replicates of six wells for all the doses and vehicle control for each experiment. ${ }^{*}<0.001$, statistically significant (Student's $t$-test). (b) Bortezomib treatment initially causes $\mathrm{G}_{2}-\mathrm{M}$ arrest at $24 \mathrm{~h}$ treatment leading to accumulation of Apo fraction of cell cycle in EOC cells after $48 \mathrm{~h}$. MDAH2774 cells were treated with 10, 100, 500 and $1000 \mathrm{nM}$ bortezomib for 24 and $48 \mathrm{~h}$. Thereafter, the cells were washed, fixed and stained with propidium iodide (PI), and analyzed for DNA content by flow cytometry as described in Materials and Methods. (c) Bortezomib-induced apoptosis detected by Annexin V/PI dual staining. MDAH2774 cells were treated with various doses of bortezomib (as indicated) for $48 \mathrm{~h}$ and cells were subsequently stained with fluorescein-conjugated Annexin $\mathrm{V}$ and $\mathrm{Pl}$.

of bortezomib and the cell-cycle status was analyzed by flow cytometry after staining with PI. As shown in Figure 2b, after $24 \mathrm{~h}$ treatment with bortezomib, the percentage of cells in $\mathrm{G}_{0}-\mathrm{G}_{1}$ phase was reduced more than $60 \%$ compared with control, with the treated cells accumulating in the $\mathrm{G}_{2}-\mathrm{M}$ phase suggesting that proteasome inhibition induces cellcycle arrest rather than apoptosis after $24 \mathrm{~h}$ treatment. To confirm these findings, we analyzed cells after $24 \mathrm{~h}$ treatment with bortezomib with Annexin V/PI dual staining and were not able to detect appreciable amount of apoptosis when compared with the untreated control sample (data not shown). However, after $48 \mathrm{~h}$ of treatment with different doses of bortezomib, we detected a shift of cells to the sub- $G_{1}$ phase as compared to the control sample. The sub- $\mathrm{G}_{1}$ population of cells increased from $1.24 \%$ in the untreated control sample to $16.66 \%$ after $50 \mathrm{nM}$ treatment, $22.67 \%$ after $100 \mathrm{nM}$ treatment and $28.61 \%$ after $500 \mathrm{nM}$ treatment in MDAH2774 cells. This increase in the sub- $G_{1}$ population was accompanied by a dose-dependent decrease in the percentage of cells in the $\mathrm{G}_{2}-\mathrm{M}$ phase. It has been reported that cells with these features die due to apoptosis.

To further confirm that this increase in the sub- $G_{1}$ is indeed apoptotic, EOC cell lines were treated with various doses of bortezomib for $48 \mathrm{~h}$ and the cells were stained with FITC-conjugated Annexin V and PI. As shown in Figure 2c, there was a dose-dependent increase in the apoptotic cells in 
MDAH2774 cell line as seen by an increase of cells in the upper right quadrant depicting apoptotic cells. Similar data were obtained using other ovarian cancer cell line (SKOV3). One additional method-the analysis of DNA fragmentation status, a hallmark of apoptosis-was used to further confirm apoptosis in response to bortezomib. MDAH2774 cells were treated with bortezomib for $48 \mathrm{~h}$. Bortezomib treatment caused DNA laddering in a dose-dependent manner (data not shown), confirming that the cells were actually dying of apoptosis.

Progression through the phases of cell cycle is regulated by periodic activation of several cyclin-dependent kinases (CDK) whose levels are controlled through ubiquitination and proteasomal degradation. ${ }^{36-39}$ In particular, levels of CDK inhibitors p27Kip1 have been shown previously to be dysregulated following proteasomal inhibition. ${ }^{40-44}$ There are number of studies that show SKP2 having an essential role in degradation of p27Kip $1 .{ }^{11-13}$ In view of these findings, we sought to determine whether bortezomib-induced apoptosis is due to degradation of SKP2. EOC cell lines were treated with 10, 50, 100, 500 and $1000 \mathrm{nM}$ bortezomib for $48 \mathrm{~h}$. Cells were lysed and proteins were separated on SDS-PAGE and immunoblotted with SKP2. As shown in Figure 3a, bortezomib treatment caused downregulation of SKP2 and upregulation of p27Kip1 in both MDAH2774 and SKOV3 EOC cell lines. A strong inverse relation was found between SKP2 and p27Kip1 after bortezomib treatment, suggesting that bortezomib-mediated downregulation of SKP2 is an important mechanism to induce apoptosis in EOC cell lines through upregulation of p27Kip1. In addition bortezomib treatment causes dose-dependent accumulation of polyubiquitinated proteins (Figure $3 \mathrm{~b}$ ). To provide direct evidence whether downregulation of SKP2 upregulates p27Kip1, we attempted to inhibit SKP2 expression in MDAH2774 cells by siRNA strategy. For this purpose, SKP2 activity was blocked by expression using siRNA against SKP2. As expected in Figure 3c, transfection of siRNA against SKP2 resulted in SKP2 protein depletion as well as concomitant accumulation of p27Kip1 in MDAH2774 cell line.

\section{Bortezomib Enhanced Antitumor Effects of Cisplatin}

To determine whether bortezomib in combination with other chemotherapeutic agents might increase its antitumor effects, we treated MDAH2774 cells with subtoxic doses of bortezomib $(50 \mathrm{nM})$ and cisplatin $(10 \mu \mathrm{M})$, alone or in combination of bortezomib and cisplatin. As shown in Figure 4a, the combination of bortezomib and cisplatin reduced cell proliferation $(<0.01)$ significantly more than bortezomib or cisplatin alone. Under same treatment condition similar results were obtained using SKOV3 cell lines (data not shown). In the next series of experiments, we evaluated the effect of bortezomib and cisplatin alone in combination of these drugs on induction apoptosis in EOC cell lines. The combination treatment of MDAH2774 cells resulted more apoptotic cells as compared to single drug treatment alone

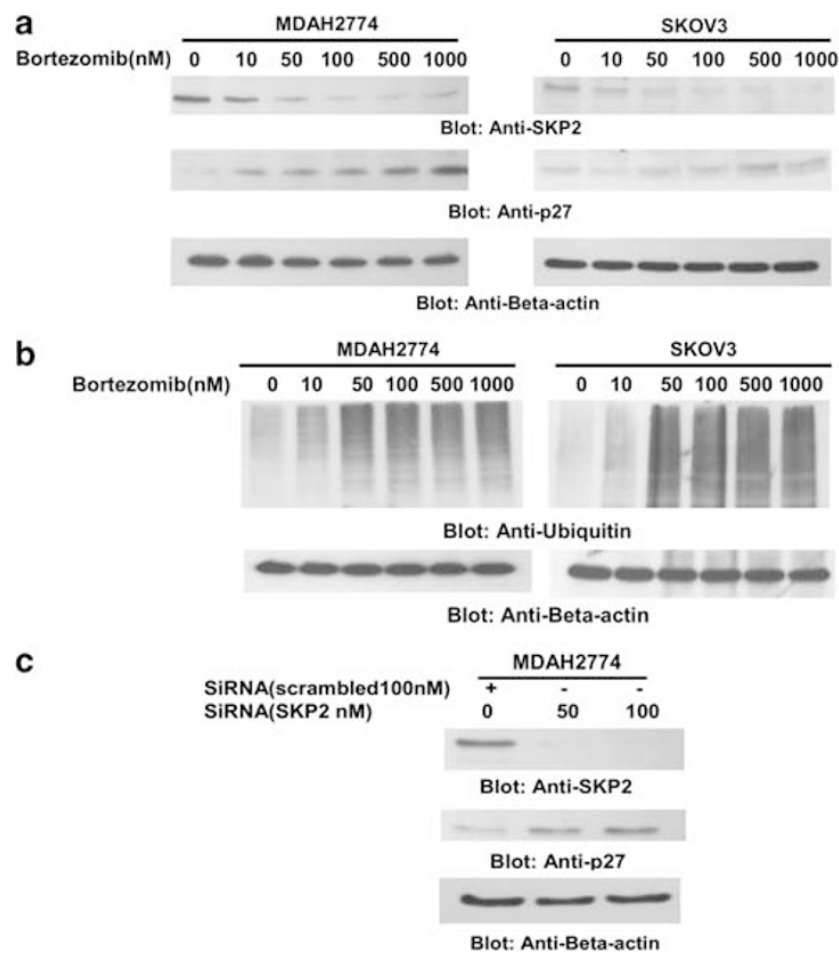

Figure 3 Downregulation of SKP2 pathway by proteasome inhibition causes accumulation of ubiquitinated proteins and upregulates the expression of p27Kip1. (a) Bortezomib treatment downregulated expression of SKP2 and increased level of p27Kip1. MDAH2774 and SKOV3 cells were treated with and various doses of bortezomib as indicated for $48 \mathrm{~h}$. After cell lysis, equal amounts of proteins were separated by SDS-PAGE, transferred to Immobilon membrane, and immunoblotted with antibodies against SKP2, p27Kip 1 and $\beta$-actin as indicated. (b) Bortezomib treatment mediates various ubiquitinated proteins in EOC cells. MDAH2774 and SKOV3 cells were treated with and various doses of bortezomib as indicated for $48 \mathrm{~h}$. After cell lysis, equal amounts of proteins were separated by SDS-PAGE, transferred to Immobilon membrane, and immunoblotted with antibodies against antiubiquitin and $\beta$-actin antibodies as indicated. (c) SKP2 siRNA expression downregulates SKP2 and accumulates p27Kip1. MDAH2774 cells were transfected with scrambled siRNA (100 nM) and SKP2 siRNA (50 and $100 \mathrm{nM}$ ) with Lipofectamine as described in Materials and methods. After $48 \mathrm{~h}$ of transfection, cells were lysed and equal amounts of proteins were separated by SDS-PAGE, transferred to Immobilon membrane, and immunoblotted with antibodies against SKP2, p27Kip1 and $\beta$-actin as indicated.

(Figure $4 \mathrm{~b}$ and $\mathrm{c}$ ). We further determined the status of SKP2 and p27Kip1 in response to co-treatment of EOC cell lines with bortezomib and cisplatin. MDAH2774 cells were treated either with $50 \mathrm{nM}$ bortezomib and $10 \mu \mathrm{M}$ cisplatin, or in combination of bortezomib and cisplatin. As shown in Figure 4d, treatment with either bortezomib or cisplatin alone resulted no effect or a slight effect on SKP2 and p27Kip1 expression. However, combination treatment of bortezomib and cisplatin resulted in more profound decrease of SKP2 and accompanying increase of p27Kip1 level. These results suggests that bortezomib potentiate the anticancer effects of cisplatin in EOC cell lines. 
a

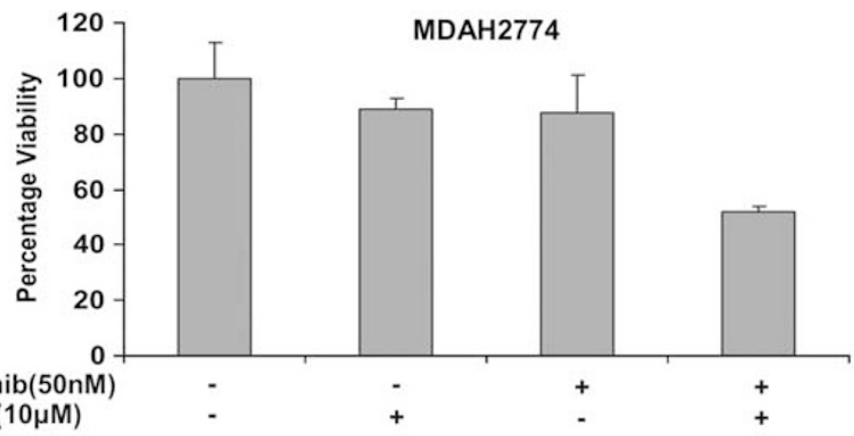

b Bortezomib(50nM)

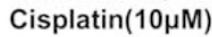

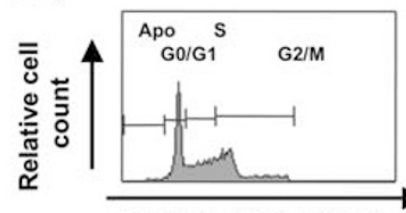

Relative DNA content

Bortezomib $(50 \mathrm{n}$
Cisplatin $(10 \mu \mathrm{M})$
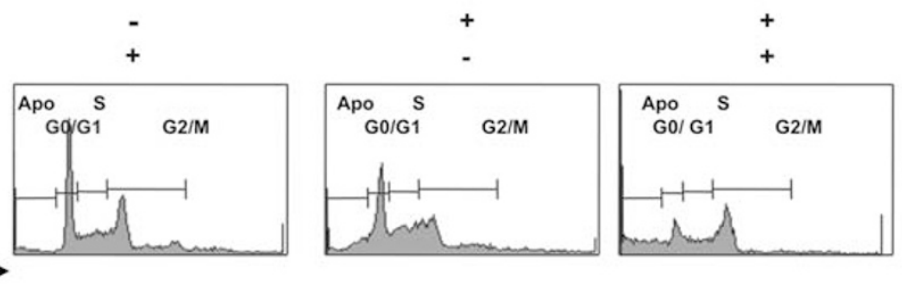

MDAH2774

$\begin{array}{ll}\text { Apo } & 1.3 \% \\ \text { G0/G1 } & 59.9 \% \\ \text { S } & 18.9 \% \\ \text { G2/M } & 20.7 \%\end{array}$

$6.7 \%$

$51.9 \%$

$21.4 \%$

$20.2 \%$

\section{Bortezomib(50nM)} Cisplatin $(10 \mu \mathrm{M})$
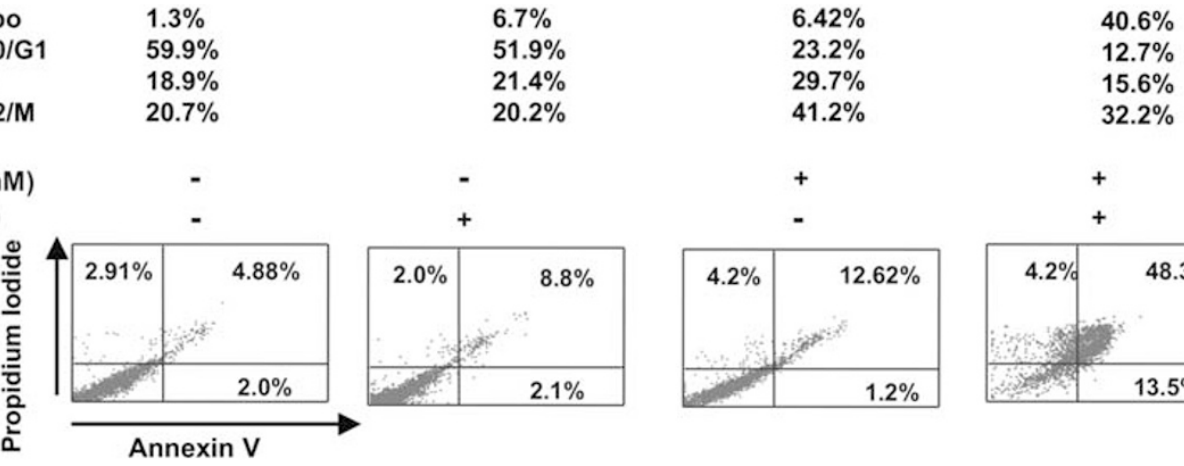

$40.6 \%$

$23.2 \%$

$29.7 \%$

$32.2 \%$

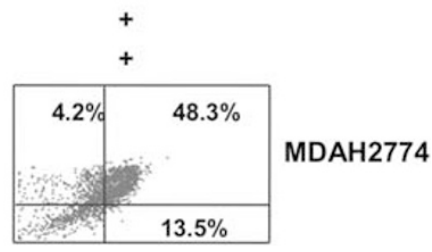

d

Bortezomib(50nM)

Cisplatin $(10 \mu \mathrm{M})$

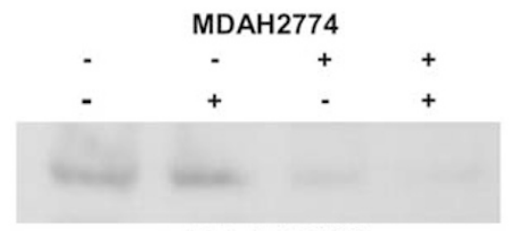

Blot: Anti-SKP2

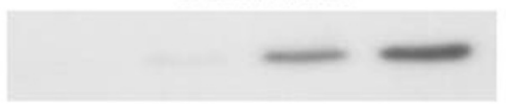

Blot: Anti-p27

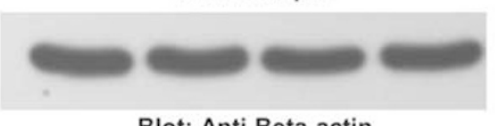

Blot: Anti-Beta-actin

Figure 4 Bortezomib augments antitumor effect of cisplatin in EOC cells. (a) Combination treatment of bortezomib and cisplatin inhibited more profound cell proliferation of EOC cells. MDAH2774 cells were treated either with $50 \mathrm{nM}$ bortezomib and $10 \mu \mathrm{M}$ cisplatin alone or with combination of $50 \mathrm{nM}$ bortezomib and $10 \mu \mathrm{M}$ cisplatin for $48 \mathrm{~h}$. Cell proliferation assays were performed using MTT as described in Materials and methods. The graph displays the mean \pm s.d. (standard deviation) of three independent experiments with replicates of four wells for all the doses and vehicle control for each experiment. ${ }^{*} P<0.001$, statistically significant (Student's $t$-test). (b) Bortezomib enhanced cisplatin Apo fraction EOC cells. MDAH2774 cells were treated either with $50 \mathrm{nM}$ bortezomib and $10 \mu \mathrm{M}$ cisplatin alone or with combination of $50 \mathrm{nM}$ bortezomib and $10 \mu \mathrm{M}$ cisplatin for $48 \mathrm{~h}$. Thereafter, the cells were washed, fixed and stained with propidium iodide (PI), and analyzed for DNA content by flow cytometry as described in Materials and methods. (c) Bortezomib enhanced cisplatin-induced apoptosis in EOC cells. MDAH2774 cells were treated either with $50 \mathrm{nM}$ bortezomib and $10 \mu \mathrm{M}$ cisplatin alone or with combination of $50 \mathrm{nM}$ bortezomib and $10 \mu \mathrm{M}$ cisplatin for $48 \mathrm{~h}$ and cells were subsequently stained with fluorescein-conjugated Annexin V and PI. (d) Effect of bortezomib and cisplatin on expression of SKP2 and p27kip1 in EOC cells. MDAH2774 cells were treated with either $50 \mathrm{nM}$ bortezomib and $10 \mu \mathrm{M}$ cisplatin alone or combination of $50 \mathrm{nM}$ bortezomib and $10 \mu \mathrm{M}$ cisplatin for $48 \mathrm{~h}$ and cells were subsequently lysed, equal amounts of proteins were separated by SDS-PAGE, and immunoblotted with antibodies against SKP2, p27Kip1 and $\beta$-actin as indicated. 


\section{Bortezomib Induces Apoptosis by Involving Mitochondrial Pathway and Activation of Caspases in EOC}

The apoptotic signaling cascade starts with activation of caspase- 8 and truncation of BID, which translocates to the mitochondrial membrane allowing activation of proapoptotic proteins and release of cytochrome $c$. Therefore, we sought to determine whether downregulation of SKP2 signaling involves mitochondria. Activated caspase- 8 is capable of cleaving caspase-3 either directly or by digesting BID to its active form (tBID), which leads to the release of cytochrome $c$ from mitochondria. Bortezomib treatment resulted in activation of caspase-8 leading to truncation of BID in MDAH2774 cells (Supplementary Figure 2A) as inferred by the decreased intensity of the full-length BID band. We then tested the effect of bortezomib on the mitochondrial membrane potentials in these cells. Cells were treated with bortezomib for $48 \mathrm{~h}$ and labeled with JC1 dye and mitochondrial membrane potential was measured by flow cytometry. As shown in Supplementary Figure 2B, inhibition of proteasome resulted in loss of mitochondrial membrane potential in EOC cells as measured by JC1-stained green fluorescence depicting apoptotic cells. We then studied cytochrome $c$ release from mitochondria in cells treated for $48 \mathrm{~h}$ with bortezomib. Cytochrome $c$ was released to the cytosol after bortezomib treatment in MDAH2774 cells (Supplementary Figure 2C). On the other hand, the level of cytochrome $c$ decreased in mitochondrial fraction of MDAH2774 cells. These results suggest that inhibition of proteasome pathways disrupts the mitochondrial membrane potential leading to the release of cytochrome $c$ to the cytosol. We then sought to determine whether bortezomibinduced release of cytochrome $c$ is capable of activation of caspases-3 and PARP. Figure 5a shows that bortezomib treatment resulted in the activation of caspase- 3 and cleavage of PARP in MDAH2774 and SKOV3. These results are consistent with the data on cytochrome $c$ release and indicate that activation of effectors caspases is involved in bortezomib-induced apoptosis in EOC cells. In addition, pretreatment of MDAH2774 cells with $80 \mu \mathrm{M} \mathrm{z}$-VAD-fmk, a universal inhibitor of caspases, abrogated apoptosis and prevented apoptosis and caspase-3 and PARP activation induced by bortezomib (Supplementary Figure 3), clearly indicating that caspases are critical in bortezomib-induced apoptosis in EOC cells.

Inhibitors of apoptosis proteins (IAP) have been shown to have direct effects on caspases. ${ }^{45} \mathrm{We}$, therefore, also examined whether bortezomib induces cell death by modulating the expression of IAP family members that ultimately determine the cell response to apoptotic stimuli. EOC cell lines were treated with various doses of bortezomib for $48 \mathrm{~h}$ and expression of XIAP and survivin was determined using western blotting. As shown in Figure 5b, bortezomib treatment caused downregulation of XIAP and survivin. These results implicate that these survival proteins may be

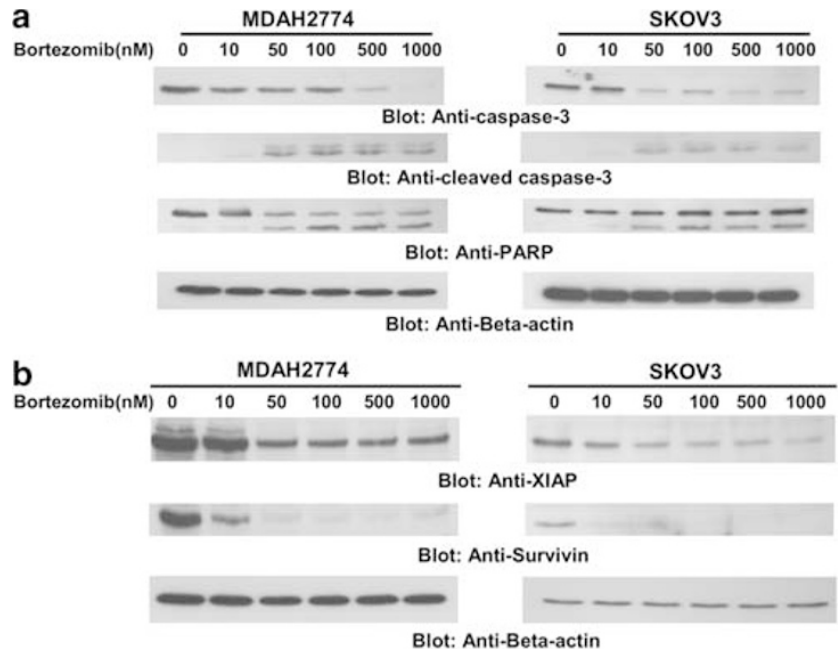

Figure 5 Activation of caspases-3 and cleavage of PARP induced by bortezomib treatment in EOC cells. (a) Caspases-3 and PARP cleavage following bortezomib treatment. MDAH2774 and SKOV3 cells were treated with and bortezomib for $48 \mathrm{~h}$. Cells were lysed and $20 \mu \mathrm{g}$ protein was separated by SDS-PAGE, transferred to PVDF membrane, and immunoblotted with antibodies against procaspase-3, cleaved caspase-3, PARP and $\beta$-actin. (b) Bortezomib-induced downregulation of XIAP and survivin expression. Cells were lysed and equal amount of proteins were MDAH2774 and SKOV3 cells were treated with various doses of bortezomib as indicated for $48 \mathrm{~h}$, separated on SDS-PAGE, transferred to PVDF membrane, and immunoblotted with antibodies against XIAP, survivin and $\beta$-actin as indicated.

modulated by proteasomal inhibition for the survival of EOC cells.

\section{In Vivo Activity of Proteasome Inhibitor Bortezomib against EOC Xenograft}

The proteasome inhibitor bortezomib (Velcade) has shown efficacy for the treatment of multiple myeloma as well as other hematological and solid tumors. ${ }^{46,47}$ Our observation that EOC cancer cells, like multiple myeloma, exhibit enhanced sensitivity to proteasome inhibitor-induced apoptosis in vitro suggests the potential for therapeutic responses to treatment of EOC cancer with proteasome inhibitors in vivo. Therefore, the ability of proteasome inhibitor bortezomib to inhibit EOC tumor growth was examined with a mouse xenograft model of EOC cancer. Nude mice were inoculated s.c. in the right abdominal quadrant with five million MDAH2774 cells. After 1 week, mice were randomly assigned in two groups. Mice were then treated with bortezomib (bortezomib treatment group, $1 \mathrm{mg} / \mathrm{kg} ; n=5$ and $2 \mathrm{mg} / \mathrm{kg}$; $n=5)$ or $(0.9 \%)$ normal saline (saline-treated control groups, $n=5$ ) and received i.p. injection twice weekly. After 4 weeks of treatment, mice were killed and tumors were collected. As shown in Figure 6a, bortezomib treatment causes a time-dependent regression of MDAH2774 xenograft tumor in mice as compared to vehicle-treated mice. The regression reached significance $(P<0.05)$ at the end of fourth week of treatment by bortezomib. A significant reduction in 


\section{MDAH2774 xenografts}

a

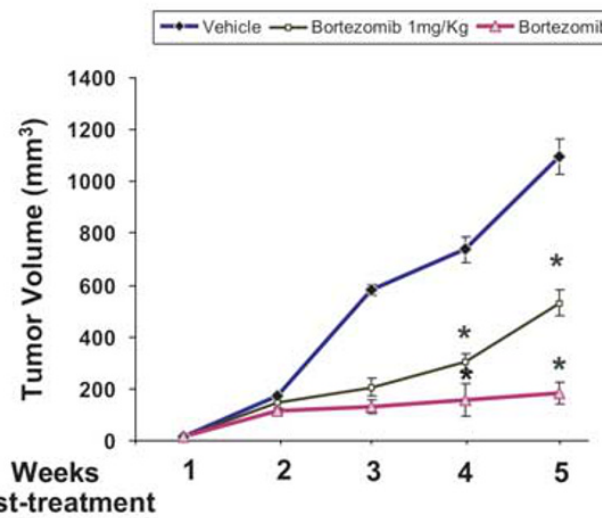

C

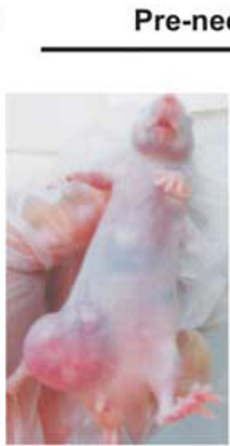

Vehicle

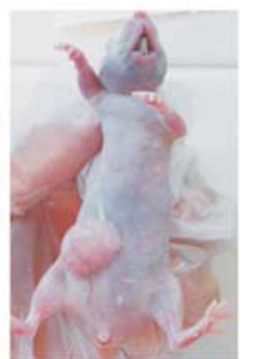

Bortezomib $1 \mathrm{mg} / \mathrm{kg}$

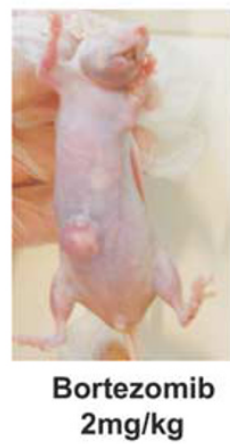

$2 \mathrm{mg} / \mathrm{kg}$ b

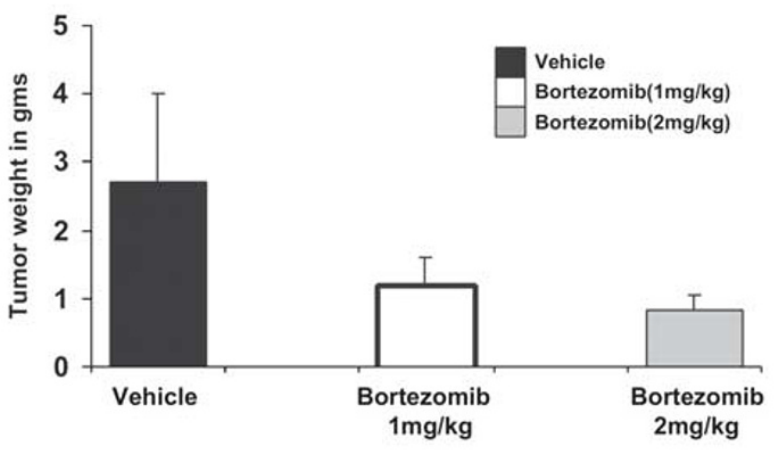

Post-necropsy MDAH2774 xenografts

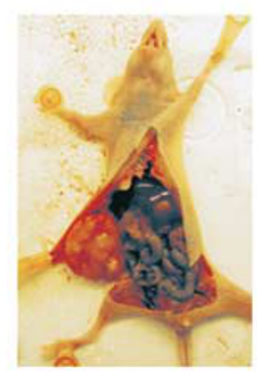

Vehicle

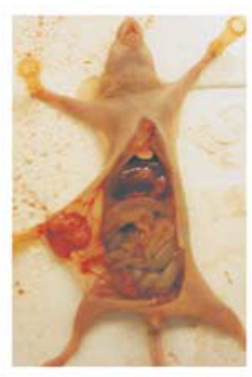

Bortezomib $1 \mathrm{mg} / \mathrm{kg}$

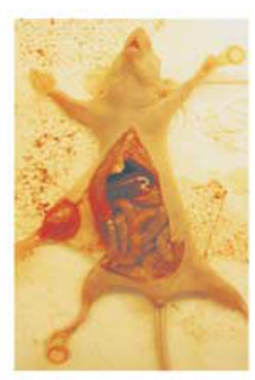

Bortezomib $2 \mathrm{mg} / \mathrm{kg}$

\section{d MDAH2774 xenografts}

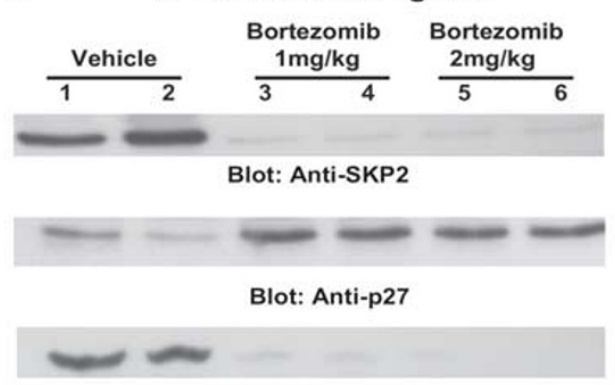

Blot: Anti-caspase-3

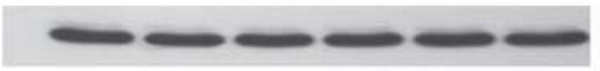

Blot: Anti-Beta-actin

Figure 6 Bortezomib treatment inhibits growth of MDAH2774 xenograft and downregulates SKP2 and increases levels of p27Kip1 in vivo. Nude mice at 6 weeks of age were injected i.p. with $5 \times 10^{6} \mathrm{MDAH} 2774$ cells. After 1 week, mice were treated with bortezomib at 1 and $2 \mathrm{mg} / \mathrm{kg}$ per dose or with 5\% DMSO in PBS as a vehicle control. (a) Inhibition of MDAH2774 tumor growth by bortezomib. The volume of each tumor was measured every week after the start of treatment. The average $(n=5)$ tumor volume in vehicle-treated control mice and treated with bortezomib was plotted, ${ }^{\star} P<0.05$. (b) After 4 weeks of treatment, mice were killed and tumor weights were measured. ${ }^{*} P<0.05$, compared to vehicle-treated mice by Student's $t$-test. (c) Representative tumor images of vehicle- and bortezomib-treated mice before and after necropsy. The lower panel images are with $\times 10$ magnification. (d) Whole-cell homogenates of individual tumor were prepared and western blot analyses of SKP2, p27Kip1, caspase-3 and actin were carried out as described in Materials and Methods.

tumor weight (Figure 6b) was observed in mice treated with bortezomib compared to the control group $(P<0.05)$. In addition, images of tumor before and after necropsy showed that bortezomib treatment resulted in shrinkage of tumor size (Figure 6c). Because our in vitro data showed that bortezomib treatment downregulated SKP2 and subsequently 
induced the expression of p27Kip1 in MDAH2774 cell line, we tested whether proteasome inhibition in vivo altered the expression of these proteins. We carried out western blot analysis to analyze the SKP2 and p27Kip1 levels in primary tumors derived from vehicle-treated mice and in mice treated with bortezomib. As shown in Figure 6d, the level of SKP2 was markedly decreased in mice treated with bortezomib as compared to vehicle-treated mice and on the other hand level of p27Kip1 was increased, which resulted in activation of caspase-3, a hallmark of apoptosis. It is also noteworthy that animal treated with proteasome inhibitors did not exhibit weight loss (data not shown).

\section{DISCUSSION}

The expression of SKP2, the F-box protein that targets p27Kip1 for degradation, is commonly overexpressed in human cancers. ${ }^{48}$ SKP2 protein enables efficient transfer of ubiquitin of $\mathrm{p} 27 \mathrm{Kip} 1$, resulting in rapid proteasome-mediated degradation. ${ }^{11}$ Previous studies using purified extract from primary colon cancer tissue suggested that increased degradation of p27Kip1 by SKP2-dependent mechanism correlated with increased aggressiveness of the respective tumor. The interaction between these proteins was evident in a significant proportion of the study tumor samples, whereby the expression of SKP2 was inversely associated with p27Kip1 protein levels. ${ }^{49}$ We therefore determined the function of both SKP2 and p27Kip1 as prognostic markers and found that those EOC samples that exhibited deregulation of SKP2 and p27Kip1, ie, high level of SKP2 and low level of p27Kip1, were strongly associated with proliferative marker Kil67. These clinical data as well as recent findings in cell lines and mice that suggest a potential role of SKP2-mediated p27Kip1 turnover have increased tendency of intestinal tumors to progress to a more malignant state. ${ }^{50,51}$. Our data showed that bortezomib treatment of EOC cells downregulated the expression of SKP2 with reciprocal upregulation of p27Kip1, a well-known target of proteasome. ${ }^{52}$ Inhibition of SKP2 expression by specific SKP2 siRNA increased p27Kip1 levels strongly suggesting that bortezomib-mediated downregulation of SKP2 and upregulation p27Kip1 likely have a significant role in the induction of apoptosis in ovarian cancer cell lines. Apoptosis is a multistep process and an increasing number of genes have been identified that are involved in the control or execution of apoptosis. ${ }^{53}$ Our study shows that proteasomal inhibition by bortezomib in EOC cell caused apoptosis by activation of caspase- 8 and truncation of BID, which translocates to the mitochondrial membrane allowing activation of proapoptotic proteins and release of cytochrome $c$ into cytosole. Released cytochrome $c$ results in the formation of apoptosome by interaction with apaf1 and caspase-9, leading to the activation of caspase-3, eventually resulting in cleavage of PARP in apoptotic cells; a hallmark of apoptosis by various antitumor agents. ${ }^{54}$ Furthermore, pretreatment of EOC cells with a broadspectrum caspase inhibitor abrogated the bortezomib- induced apoptosis. These data suggest that inhibition of ubiquitin-proteasome in EOC induced apoptosis by caspasecascade activation. Our in vivo studies further validate our hypothesis that treatment of mice bearing palpable EOC xenograft with bortezomib cause retarded tumor growth by downregulation of SKP2 and increased level of p27Kip1 consistent with the in vitro effect of the proteasome inhibitors.

Bortezomib represent a novel class of myeloma therapy, several studies have shown the efficacy of the proteasome inhibitor bortezomib in variety of tumor cell lines and its synergistic antitumor activity has been shown in combination with other chemotherapy. ${ }^{55-57}$ Several studies have shown that proteasome inhibitors induce upregulation of tumor suppressor genes, $p 21$ and $p 27$, by inhibition of other survival proteins including NF $\kappa \mathrm{B}^{58}{ }^{58}$ Furthermore, bortezomib treatment showed synergistic antiproliferative and proapoptotic effects when combined with Map kinase and EFGR inhibitor in in vitro studies. ${ }^{59,60}$

Our in vitro data confirm a sensitivity of EOC cells to proteasomal inhibition and this apoptotic response is significantly enhanced after combination therapy using cisplatin with bortezomib. Such selectivity suggests proteasome inhibitors may be a new candidate of chemotherapeutic agent for EOC treatment alone or in combination with other conventional chemotherapeutic agents.

Together our results establish that the SKP2 ubiquitinproteasome has a role in the growth and survival of EOC cells. Downregulation of SKP2 expression results in accumulation and stabilization of p27Kip1, leading to the induction of apoptosis in EOC cells through release of cytochrome $c$ from the mitochondria and activation of downstream caspases. In addition, EOC subgroup of patients with high SKP2 expression and low level of p27Kip1 show a poor overall survival. These studies may have important implications for future preclinical and clinical studies in EOC. Indeed, they may pave the way for investigations aimed at determining the usefulness of a novel strategy for treating EOC with inhibitors of proteasome pathways, either alone or in combination with other agents.

Supplementary Information accompanies the paper on the Laboratory Investigation website (http://www.laboratoryinvestigation.org)

\section{ACKNOWLEDGEMENT}

We thank Sriraman Devarajan for data abstraction and statistical analysis; Shakaib Siddiqui for data entry and Azadali Moorji, Saeeda Omer Ahmed, Valerie Atizado, Hassan Al-Dossari and Valorie Balde for their technical assistance.

\section{DISCLOSURE/CONFLICT OF INTEREST}

The authors declare no conflict of interest.

1. Douillard JY, Cunningham $D$, Roth $A D$, et al. Irinotecan combined with fluorouracil compared with fluorouracil alone as first-line treatment for metastatic colorectal cancer: a multicentre randomised trial. Lancet 2000;355:1041-1047. 
2. de Gramont A, Figer A, Seymour M, et al. Leucovorin and fluorouracil with or without oxaliplatin as first-line treatment in advanced colorectal cancer. J Clin Oncol 2000;18:2938-2947.

3. Ciechanover A. The ubiquitin-proteasome proteolytic pathway. Cell 1994;79:13-21.

4. Ovaa $H$, Kessler BM, Rolen $U$, et al. Activity-based ubiquitin-specific protease (USP) profiling of virus-infected and malignant human cells. Proc Natl Acad Sci USA 2004;101:2253-2258.

5. Milano A, laffaioli RV, Caponigro F. The proteasome: a worthwhile target for the treatment of solid tumours? Eur J Cancer 2007;43: 1125-1133.

6. Cusack JC, Liu R, Houston M, et al. Enhanced chemosensitivity to CPT-11 with proteasome inhibitor PS-341: implications for systemic nuclear factor-kappaB inhibition. Cancer Res 2001;61:3535-3540.

7. McDade TP, Perugini RA, Vittimberga Jr FJ, et al. Ubiquitin-proteasome inhibition enhances apoptosis of human pancreatic cancer cells. Surgery 1999;126:371-377.

8. Carrano AC, Eytan E, Hershko A, et al. SKP2 is required for ubiquitinmediated degradation of the CDK inhibitor p27. Nat Cell Biol 1999;1:193-199.

9. Sutterluty $H$, Chatelain E, Marti A, et al. p45SKP2 promotes p27Kip1 degradation and induces $S$ phase in quiescent cells. Nat Cell Biol 1999;1:207-214.

10. Tsvetkov LM, Yeh KH, Lee SJ, et al. p27(Kip1) ubiquitination and degradation is regulated by the SCF(Skp2) complex through phosphorylated Thr187 in p27. Curr Biol 1999;9:661-664.

11. Lwin T, Hazlehurst LA, Dessureault $S$, et al. Cell adhesion induces p27Kip1-associated cell-cycle arrest through down-regulation of the SCFSkp2 ubiquitin ligase pathway in mantle cell and other non-Hodgkin's B-cell lymphomas. Blood 2007;110:1631-1638.

12. Signoretti S, Di Marcotullio L, Richardson A, et al. Oncogenic role of the ubiquitin ligase subunit Skp2 in human breast cancer. J Clin Invest 2002;110:633-641.

13. Hershko D, Bornstein G, Ben-Izhak O, et al. Inverse relation between levels of p27(Kip1) and of its ubiquitin ligase subunit Skp2 in colorectal carcinomas. Cancer 2001;91:1745-1751.

14. Gstaiger M, Jordan R, Lim M, et al. Skp2 is oncogenic and overexpressed in human cancers. Proc Natl Acad Sci USA 2001;98:5043-5048.

15. Yang G, Ayala G, De Marzo A, et al. Elevated Skp2 protein expression in human prostate cancer: association with loss of the cyclin-dependent kinase inhibitor p27 and PTEN and with reduced recurrence-free survival. Clin Cancer Res 2002;8:3419-3426.

16. Soligo D, Servida F, Delia D, et al. The apoptogenic response of human myeloid leukaemia cell lines and of normal and malignant haematopoietic progenitor cells to the proteasome inhibitor PSI. Br J Haematol 2001;113:126-135.

17. Delic J, Masdehors P, Omura S, et al. The proteasome inhibitor lactacystin induces apoptosis and sensitizes chemo- and radioresistant human chronic lymphocytic leukaemia lymphocytes to TNF-alphainitiated apoptosis. Br J Cancer 1998;77:1103-1107.

18. Orlowski RZ, Eswara JR, Lafond-Walker A, et al. Tumor growth inhibition induced in a murine model of human Burkitt's lymphoma by a proteasome inhibitor. Cancer Res 1998;58:4342-4348.

19. Thornberry NA, Lazebnik Y. Caspases: enemies within. Science 1998;281:1312-1316.

20. Adams J. Proteasome inhibition in cancer: development of PS-341. Semin Oncol 2001;28:613-619.

21. Richardson PG. Bortezomib: a novel therapy approved for multiple myeloma. Clin Adv Hematol Oncol 2003;1:596-600.

22. Russel P. Surface epithelial-stromal tumors of the ovary. In: Kurman RJ (ed). Blaustein's Pathology of the Female Genital Tract. SpringerVerlag: New York, 1995, pp 705-782.

23. Bavi PP, Abubaker JA, Jehan Z, et al. Colorectal carcinomas from Middle East. Molecular and tissue microarray analysis of genomic instability pathways. Saudi Med J 2008;29:75-80.

24. Abubaker J, Bavi P, Al-Harbi S, et al. Clinicopathological analysis of colorectal cancers with PIK3CA mutations in Middle Eastern population. Oncogene 2008;27:3539-3545.

25. Bavi $P$, Jehan $Z$, Atizado $V$, et al. Prevalence of fragile histidine triad expression in tumors from Saudi Arabia: a tissue microarray analysis. Cancer Epidemiol Biomarkers Prev 2006;15:1708-1718.
26. Shapira M, Ben-Izhak O, Bishara B, et al. Alterations in the expression of the cell cycle regulatory protein cyclin kinase subunit 1 in colorectal carcinoma. Cancer 2004;8:1615-1621.

27. Newcomb EW, Sosnow M, Demopoulos Rl, et al. Expression of the cell cycle inhibitor p27KIP1 is a new prognostic marker associated with survival in epithelial ovarian tumors. Am J Pathol 1999;154:119-125.

28. Uddin S, Ahmed M, Bavi P, et al. Bortezomib (Velcade) induces p27Kip1 expression through SKP2 degradation in colorectal cancer. Cancer Res 2008;68:3379-3388.

29. Uddin S, Hussain A, Ahmed M, et al. S-phase kinase protein 2 is an attractive therapeutic target in a subset of diffuse large B-cell lymphoma. J Pathol 2008;216:483-494.

30. Hussain AR, Al-Jomah NA, Siraj AK, et al. Sanguinarine-dependent induction of apoptosis in primary effusion lymphoma cells. Cancer Res 2007;67:3888-3897.

31. Uddin S, Hussain AR, Manogaran PS, et al. Curcumin suppresses growth and induces apoptosis in primary effusion lymphoma. Oncogene 2005;24:7022-7030.

32. Uddin S, Ah-Kang J, Ulaszek J, et al. Differentiation stage-specific activation of p38 mitogen-activated protein kinase isoforms in primary human erythroid cells. Proc Natl Acad Sci USA 2004;101:147-152.

33. Uddin S, Hussain AR, Al-Hussein KA, et al. Inhibition of phosphatidylinositol 3'-kinase/AKT signaling promotes apoptosis of primary effusion lymphoma cells. Clin Cancer Res 2005;11:3102-3108.

34. Uddin S, Hussain AR, Siraj AK, et al. Role of phosphatidylinositol $3^{\prime}$-kinase/AKT pathway in diffuse large B-cell lymphoma survival. Blood 2006;108:4178-4186.

35. Holst F, Stahl PR, Ruiz C, et al. Estrogen receptor alpha (ESR1) gene amplification is frequent in breast cancer. Nat Genet 2007;39:655-660.

36. Glotzer M, Murray AW, Kirschner MW. Cyclin is degraded by the ubiquitin pathway. Nature 1991;349:132-138.

37. Levkau B, Koyama H, Raines EW, et al. Cleavage of p21Cip1/Waf1 and p27Kip1 mediates apoptosis in endothelial cells through activation of Cdk2: role of a caspase cascade. Mol Cell 1998;1:553-563.

38. Coulombe $\mathrm{P}$, Rodier $\mathrm{G}$, Bonneil $\mathrm{E}$, et al. N-terminal ubiquitination of extracellular signal-regulated kinase 3 and p21 directs their degradation by the proteasome. Mol Cell Biol 2004;24:6140-6150.

39. Pagano M, Tam SW, Theodoras AM, et al. Role of the ubiquitinproteasome pathway in regulating abundance of the cyclindependent kinase inhibitor p27. Science 1995;269:682-685.

40. Adams J, Palombella VJ, Sausville EA, et al. Proteasome inhibitors: a novel class of potent and effective antitumor agents. Cancer Res 1999;59:2615-2622.

41. Dulic V, Stein GH, Far DF, et al. Nuclear accumulation of p21Cip1 at the onset of mitosis: a role at the $\mathrm{G}_{2}-\mathrm{M}$-phase transition. Mol Cell Biol 1998;18:546-557.

42. Yin D, Zhou H, Kumagai T, et al. Proteasome inhibitor PS-341 causes cell growth arrest and apoptosis in human glioblastoma multiforme (GBM). Oncogene 2005;24:344-354.

43. Hideshima T, Richardson $P$, Chauhan D, et al. The proteasome inhibitor PS-341 inhibits growth, induces apoptosis, and overcomes drug resistance in human multiple myeloma cells. Cancer Res 2001;61: 3071-3076.

44. Chen F, Harrison LE. Ciglitazone-induced cellular anti-proliferation increases p27kip1 protein levels through both increased transcriptional activity and inhibition of proteasome degradation. Cell Signal 2005;17:809-816.

45. Dan HC, Sun M, Kaneko S, et al. Akt phosphorylation and stabilization of X-linked inhibitor of apoptosis protein (XIAP). J Biol Chem 2004;279:5405-5412.

46. Gardner RC, Assinder SJ, Christie G, et al. Characterization of peptidyl boronic acid inhibitors of mammalian $20 \mathrm{~S}$ and $26 \mathrm{~S}$ proteasomes and their inhibition of proteasomes in cultured cells. Biochem J 2000;2:447-454.

47. Rivett AJ, Gardner RC. Proteasome inhibitors: from in vitro uses to clinical trials. J Pept Sci 2000;6:478-488.

48. Ganoth D, Bornstein G, Ko TK, et al. The cell-cycle regulatory protein Cks1 is required for SCF(Skp2)-mediated ubiquitinylation of p27. Nat Cell Biol 2001;3:321-324.

49. Chiappetta G, De Marco C, Quintiero A, et al. Overexpression of the S-phase kinase-associated protein 2 in thyroid cancer. Endocr Relat Cancer; 14:405-420. 
50. Timmerbeul I, Garrett-Engele CM, Kossatz U, et al. Testing the importance of p27 degradation by the SCFskp2 pathway in murine models of lung and colon cancer. Proc Natl Acad Sci USA 2006;38:14009-14014.

51. Bazzaro M, Lee MK, Zoso A, et al. Ubiquitin-proteasome system stress sensitizes ovarian cancer to proteasome inhibitor-induced apoptosis. Cancer Res 2006;66:3754-3763.

52. Mani A, Gelmann EP. The ubiquitin-proteasome pathway and its role in cancer. J Clin Oncol 2005;23:4776-4779.

53. Gastman BR. Apoptosis and its clinical impact. Head Neck 2001;23:409-425.

54. Nunez G, Benedict MA, Hu Y, et al. Caspases: the proteases of the apoptotic pathway. Oncogene 1998;24:3237-3245.

55. Richardson P. Clinical update: proteasome inhibitors in hematologic malignancies. Cancer Treat Rev 2003;29(Suppl 1):33-39.

56. Sunwoo JB, Chen Z, Dong G, et al. Novel proteasome inhibitor PS-341 inhibits activation of nuclear factor- $\kappa$ B, cell survival, tumor growth, and angiogenesis in squamous cell carcinoma. Clin Cancer Res 2001;7:1419-1428

57. Frankel $A$, Man $S$, Elliott $P$, et al. Lack of multicellular drug resistance observed in human ovarian and prostate carcinoma treated with the proteasome inhibitor PS-341. Clin Cancer Res 2000;6: 3719-3728.

58. Cusack Jr JC, Liu R, Xia L, et al. NPI-0052 enhances tumoricidal response to conventional cancer therapy in a colon cancer model. Clin Cancer Res 2006;12:6758-6764.

59. Navas TA, Nguyen AN, Hideshima T, et al. Inhibition of p38alpha MAPK enhances proteasome inhibitor-induced apoptosis of myeloma cells by modulating $\mathrm{Hsp} 27, \mathrm{Bcl}-\mathrm{X}(\mathrm{L}), \mathrm{Mcl}-1$ and $\mathrm{p} 53$ levels in vitro and inhibits tumor growth in vivo. Leukemia 2006;20: 1017-1027.

60. An J, Rettig MB. Epidermal growth factor receptor inhibition sensitizes renal cell carcinoma cells to the cytotoxic effects of bortezomib. Mol Cancer Ther 2007;6:61-69. 